\title{
El integrismo católico y sus construcciones semánticas del enemigo para la justificación del golpe de Estado en Chile. El caso de las revistas Fiducia y Tizona, 1965-1973 1
}

\author{
Fabián Gaspar Bustamante Olguín²
}

\begin{abstract}
Resumen
En este artículo se analiza la construcción semántica del enemigo en el integrismo católico chileno a través de los usos lingüísticos de las revistas Fiducia y Tizona para justificar el golpe de Estado de 1973. La tesis que sostiene es que los usos lingüísticos de estas revistas construyeron un modelo de enemigo a combatir, de múltiples rostros, que actuaba en distintos terrenos, lo cual permitió la justificación de un orden dictatorial refundacional.
\end{abstract}

Palabras clave: Integrismo católico, Extrema derecha, Golpe de Estado, Usos lingüísticos.

\begin{abstract}
This article analyses semantic constructions about the enemy developed by the Chilean catholic integrism through linguistic uses in magazines such as Fiducia and Tizona in order to justify the 1973 Chilean Coup' d etat. The article suggests those linguistic uses built a model of an enemy to fight against; an enemy with various faces and presence in different areas. This allowed to justify the new dictatorship order.
\end{abstract}

Key words: catholic integrism, extreme right, Coup' d etat, linguistic uses.

\section{Resumem}

Neste artigo se analisa a construção semântica do inimigo no integrismo católico chileno através dos usos linguísticos das revistas Fiducia e Tizona 
para justificar o golpe de Estado de 1973. A tese que sustenta é que os usos linguísticos destas revistas construíram um modelo de inimigo a combater, de múltiplos rostos, que atuava em distintos terrenos, o qual permitiu a justificação de uma ordem ditatorial refundacional.

Palavras chave: Integrismo católico, Extrema direita, Golpe de Estado, Usos linguísticos.

En el presente artículo abordaremos a un sector de la derecha chilena (que hemos denominado integrista católica), representada por las revistas Fiducia y Tizona, que incidieron en la forma semántica con que militares y civiles validaron y justificaron el golpe de Estado de 1973. Al respecto, como es sabido, el golpe estableció el terrorismo de Estado como metodología cotidiana (que procedió a la eliminación del enemigo "marxista") en base a una justificación providencialista en la cual civiles y militares recurrieron a mitos de "conspiración subversiva" que alimentaron su accionar e hicieron de ellos los depositarios de la "verdad nacional" ante un enemigo de categorías indefinidas (semantizado como todo aquello que alteraba el orden). De allí que un aspecto importante a considerar es que tales mitos se construyeron con el propósito de generar miedo en algunos sectores sociales (sobre todo en las clases pudientes) resultando útil para los efectos de la violencia y a los imaginarios maniqueos expresados en códigos binarios, a saber: "Chile/Bien absoluto versus el Mal absoluto (Corvalán, 2009). Este último, por cierto, con diferentes denominaciones como "marxismo", "politiquería", "antipatria", "católicos progresistas" o "humanoides"3.

Desde ya cabe señalar que todas estas denominaciones actuaron como referentes negativos, con un alto grado de ambigüedad semántica, es decir, designaban a diversos enemigos sólo por el hecho de no adscribir a la posterior dictadura militar, lo que convertía a esos sujetos en blanco de su odio y destrucción mediante cualquier forma. En ese sentido, la construcción del enemigo en estas revistas fue instrumento de formación para una "lucha a muerte" entre el bien y el mal que, desde los gobiernos de Eduardo Frei Montalva y Salvador Allende, se estaban difundiendo en sus usos lingüísticos para preparar el "combate decisivo" que culminó en 1973.

3 Término acuñado por el Almirante José Toribio Merino - un rabioso anticomunista y admirador del dictador integrista católico Francisco Franco- para referirse no sólo a los "marxistas" sino que a todo tipo de oposición. La demonización del enemigo era patente en el discurso de Merino quien, en una entrevista en 1989, señalaba: Dios nos hizo a todos con alma, pero el demonio se las sacó a algunos, a los humanoides". Dentro de esta lógica, el "enemigo" estaba desprovisto de derechos humanos. Véase José Toribio Merino (1998: 515). 
Agréguese a lo anterior, por su parte, que sus usos lingüísticos respondieron a los contextos lingüísticos caracterizados por el enfrentamiento discursivo en un contexto de Guerra Fría donde aparecían las ideas del bien y mal. Al respecto cabe subrayar que estas revistas no estaban destinadas al enfrentamiento "cara a cara" con el enemigo -entiéndase los partidos de izquierda y la Democracia Cristiana-, sino que debatían enfocándose en los lectores de derecha. Ello por cuanto permitía fortalecer una "identidad conservadora reaccionaria" de un cierto sector de la derecha, más que incidir en el debate político de la época. Sobre este punto es importante enfatizar que estas revistas (en particular, Fiducia) no fueron el eje refundacional de la derecha ${ }^{4}$, sino más bien fueron fuentes que contenían un discurso de fácil integración e incorporación que les permitió obtener un componente de "identidad subjetiva" generando una sensación de "cruzada" permanente.

Así, pues, la tesis principal de este artículo es que los usos lingüísticos de estas revistas construyeron un modelo de enemigo a combatir, de múltiples rostros, que actuaba en distintos terrenos, lo cual permitió la justificación de un orden dictatorial refundacional.

\section{Fiducia5: La propiedad privada como Ley de Dios y la lucha en contra del "socialismo igualitario" del gobierno de Eduardo Frei Montalva en 1965}

Se podría sostener que el uso lingüístico que utilizó Fiducia entre el período de 1963 a 1970 -período de circulación de la revista- estuvo enfocado en dos ejes: el primero, en contra de los sectores católicos que estaban por las reformas del Concilio Vaticano Il; y el segundo -relacionado con lo anterior-

4 Proceso ocurrido a mediados de la década del sesenta que tuvo como consecuencia la desaparición de los partidos Conservador y Liberal para dar paso al nacimiento del Partido Nacional en 1966.

5 En septiembre de 1962, un grupo de jóvenes estudiantes católicos de la Pontificia Universidad Católica y de Chile se aglutinaron en torno a la revista Fiducia (en latín, confianza), organización católica de extrema derecha. Sus fundadores fueron Eduardo Larraín Bustamante, Maximiliano Griffin Ríos, Alfredo Mac Hale Espinoza, entre otros, todos ellos pertenecientes al Partido Conservador. Cabe señalar que la fundación de esta organización se debe a los contactos personales e invitaciones de estos jóvenes con la Sociedade Brasileira de Defesa da Tradição, Família e Propriedade (Sociedad Brasileña de Defensa de la Tradición, Familia y Propiedad - TFP), fundada por el intelectual brasileño Plinio Correa de Oliveira en 1960. Fiducia fue una publicación mensual que dejó de aparecer, sin previo aviso, en 1970, siendo su último número el 31 correspondiente a enero de 1970, hasta la dictadura militar, momento en que inició una nueva etapa. Demás está decir que el logotipo de la revista fue la imagen de un caballero cruzado quien sostenía un lienzo con el nombre de la revista. En 1967 Fiducia adquirió "personalidad jurídica" y pasó a llamarse Sociedad Chilena de Defensa de la Tradición, Familia y Propiedad (TFP), aunque fueron conocidos siempre como Fiducia. 
en torno al proyecto de modificación del artículo 10 concerniente al derecho de propiedad que estaba llevando a cabo Eduardo Frei Montalva. Al respecto cabe señalar que los partidos de derecha (Partido Conservador y Liberal) -junto al diario El Mercurio- ${ }^{6}$, apelaron a un discurso irrestricto en defensa de la propiedad a través del debate parlamentario y académico; mientras que el integrismo católico entró en escena con un discurso en el que la propiedad adquiría un carácter sacrosanto que, de alguna manera, cambiaba la forma de argumentación al entenderla como una discusión natural. En ese sentido, el argumento propuesto por Fiducia fue que la propiedad privada, en tanto que principio básico de derecho natural, no podía ser cuestionada ni mucho menos modificada, ya que al hacerlo se estaría atentando contra Dios y la civilización cristiana.

Esta simple y radical argumentación dejaba en claro que las reformas propuestas por el gobierno de Frei eran anticristianas. Cuestión que era inaceptable para el integrismo católico, sobre todo si los miembros del gobierno se declaraban "cristianos". A partir de ahí el objetivo del debate en Fiducia tenía como propósito dos aspectos: por un lado, infundir miedo en las clases propietarias e incentivar la violencia; y por otro, plantear la idea de que el gobierno de Frei escondía su "tendencia hacia el marxismo".

Con tal propósito, la revista semantizó a los católicos democratacristianos como de "tercera posición". En esa línea, Héctor Riesle escribió un artículo titulado El derecho de propiedad privada y la "Tercera Posición", de noviembre de 1964, en donde apuntaba a la incompatibilidad existente entre catolicismo y marxismo que estaban realizando algunos militantes democratacristianos.

El igualitarismo revolucionario reinante en nuestros tiempos parece haber elegido a la propiedad privada como el objetivo predilecto de sus ataques. Y esto se ve no sólo entre los revolucionarios más virulentos, como los marxistas, sino también en aquellos otros que (...) pretenden constituir una "tercera posición" frente al problema (...) No caben, lógicamente, caminos intermedios.

Dicha argumentación de Riesle, en efecto, pretendía descalificar y deslegitimar abiertamente al gobierno de Frei Montalva. Para tal propósito, el autor enfatizaba que la ciudadanía desconocía que detrás de esa "tercera posición" existía un "socialismo igualitario" que

(...) pretendía asestar un golpe artero a los derechos más sagrados. Y es así, como, hablando de reformas de estructura, de cogestión y

6 En ese contexto, la derecha en general asoció la injerencia estatal del gobierno como un acto que desestabilizaba el ahorro y el consumo. Véase El Mercurio, 1 de diciembre de 1965, p. 3. 
coparticipación obligatorias y de redistribución, o pretendiendo realizar expropiaciones indiscriminadas y confiscatorias [para] atacar el derecho de propiedad privada, sancionado por la Ley de Dios (Fiducia, No 13, noviembre, 1964: 4-5).

El "socialismo igualitario" fue la bandera que esgrimieron los columnistas de Fiducia para desacreditar todo el proceso de modificación a la propiedad y así legitimar el antiguo orden señorial que estaba siendo cuestionado no sólo desde la izquierda sino dentro del propio catolicismo. En ese sentido, el descrédito hacia el gobierno democratacristiano, en tanto que católicos de "tercera posición" (puerta de entrada al marxismo), llevó a Fiducia a descargar toda la intransigencia y violencia en contra el proyecto de reforma agraria. Prueba de ello fue el artículo de Jaime Guzmán (uno de los redactores de la Constitución de 1980) titulado El derecho de propiedad y el proyecto de reforma constitucional que instaba a las autoridades del gobierno democratacristiano a deponer tal medida y restablecer la ley natural.

Guzmán, en efecto, sostenía la tesis de que la propiedad privada era un derecho natural, base de la civilización cristiana, que estaba por encima del derecho contractualista o positivo (creado por los hombres), y que el gobierno democratacristiano pretendía violar al traspasarlo a manos del Estado,

(...) dejar el derecho de propiedad como una concesión del Estado, que se da y se quita a quien a éste le parezca, significa (...) la violación de un principio básico de derecho natural y un camino abierto para la implantación concreta a espaldas de un pueblo cristiano, de un régimen socialista y totalitario (Fiducia, $N^{\circ} 14$, diciembre-enero, 1964-1965:9).

De lo dicho nos interesa destacar en este punto la fuerza ofensiva que pretende ostentar el discurso de Fiducia en este momento tan decisivo para ellos. En los dichos de Guzmán no existía una comprensión de la propiedad como un bien económico ni como salvaguardia de los principios "democracia y libertad", como lo hacía la derecha tradicional, sino que la propiedad enfatizaba algo que iba mucho más allá: la propiedad, en tanto que orden natural, era el sustento de la civilización cristiana. Por lo tanto, al no ser una concesión del Estado, no podía ser violado por éste.

Hasta aquí queremos enfatizar que los planteamientos radicales de Fiducia sobre la inviolabilidad de la propiedad impedían no sólo su discusión sino que también cualquier tipo de diálogo con el gobierno. Todo ello, por cierto, son argumentos típicos de los fundamentalismos con afirmaciones tan categóricas como las anteriormente mencionadas. Desde ya cabe subrayar que tales argumentos tuvieron eco en sectores políticos y gremiales de derecha (como puede verse en la interpelación de Fiducia al presidente Frei Montalva) que contó con la difusión de El Mercurio y del apoyo de la 
Junta Ejecutiva del Partido Conservador; del Presidente del Partido Liberal; de la Sociedad Nacional de Agricultura; de la Sociedad de Fomento Fabril; de la Sociedad Nacional de Minería; de la Cámara Central de Comercio; de la Confederación Interamericana de la Producción y del Comercio; de la Unión Social de Empresarios Católicos; del Instituto Chileno de Administración de Empresas y de la Sociedad de Propietarios Urbanos (El Mercurio, 15 de mayo, 1965:25).

La mencionada interpelación a Frei Montalva sostenía que la aprobación de la ley de reforma agraria significaría el desconocimiento del derecho de propiedad -uno de los corolarios de la dignidad del hombre y del derecho natural querido por Dios-. Es por ello que no podían permitir que la supresión de la propiedad condujera a un orden contrario a la dignidad humana y a la misión de la Iglesia. Desde esta constatación le pidieron al presidente lo siguiente:

"I.- ¿Vuestra Excelencia considera la propiedad privada no es fundamento de la civilización cristiana? (...) III.-¿O Vuestra Excelencia es indiferente a todo esto y desea realmente, cueste lo que costare, abrir barreras a la mutilación o incluso a la abolición de la propiedad privada?" (Fiducia, № 17, mayo-junio, 1965:2).

Lamentablemente para las pretensiones de Fiducia, la interpelación no fue respondida ${ }^{7}$ despertando la violencia de su lenguaje al apuntar a Frei Montalva como "grosero" y "mal católico". Lo que tuvo como consecuencia que el presidente quedara completamente deslegitimado y señalado como un "enemigo anticristiano".

En todo caso la construcción negativa de la imagen de Frei Montalva no sorprende teniendo en cuenta las bases ideológicas de la revista en sus primeros números aparecidos en 1963. El "enemigo omnipresente" -que era la Revolución iniciada con la Reforma de Lutero en el siglo XVI- ya adquiría una fisonomía clara: el gobierno democratacristiano no sólo se había constituido en la "punta de lanza del comunismo" sino que además era parte del enemigo al cual Fiducia debía vencer.

En relación a lo anterior el artículo titulado El marxismo sin caretas de Héctor Riesle, en la edición mayo-junio de 1965, retomaba la idea de la "tercera posición" al comentar las tesis del libro El desarrollo de la nueva sociedad en

7 El director de Fiducia, Patricio Larraín Bustamante, escribió en cartas al lector en El Diario Ilustrado, esperando la respuesta del presidente Frei a la interpelación hecha por su revista; al mismo tiempo que criticaba el "ataque" del diario de gobierno La Nación al Arzobispo de La Serena, Alfredo Cifuentes, quien firmó a favor de Fiducia. Véase El Diario Ilustrado, 23 de mayo 1965, p. 3. 
América Latina de los militantes democratacristianos Julio Silva Solar y Jacques Chonchol. No es casualidad entonces que el articulista sostuviera de forma enfática, al inicio de su artículo, que las tesis de los autores iban en contra de la doctrina católica. En su objetivo de comprender el verdadero carácter de la "tercera posición" señalaba:

"(...) hay quienes no ocultan el verdadero rostro de una posición intermedia que sólo es una modalidad con que la Revolución destruye tal vez más eficazmente las reservas espirituales y morales y los valores y tradiciones de los pueblos cristianos" (Fiducia, N¹7, mayo-junio, 1965:8).

No cabe duda que los usos lingüísticos del articulista constituyeron una apología a la resignación y desigualdad natural. Además se desprende de la cita anterior que la validación de la ortodoxia católica (ante las tesis "erróneas" de Silva Solar y Chonchol) conllevaba a una actitud de adoctrinamiento religioso que debía ser encauzado mediante un modelo de comportamiento cristiano rigurosamente codificado para así marcar límites y fronteras imaginadas con el "otro". En este caso, la "verdad" católica no podía coexistir con el "error" porque era la "verdad" y por lo tanto le daba justificación al recurso de la violencia contra el "otro" para conseguir sus objetivos políticos.

\section{El manifiesto a la Nación Chilena sobre el proyecto de Reforma Agraria y sus repercusiones, 1966}

En marzo de 1966 Fiducia volvió con una nueva ofensiva en contra de Frei. Esta vez publicó un extenso documento titulado Manifiesto a la Nación chilena sobre el proyecto de Reforma Agraria del Presidente Frei, publicado en El Mercurio, el 26 de febrero de $1966^{8}$ (también aparecido en las primeras 5 páginas del número febrero-marzo de la revista integrista). En este documento la agrupación acusó que dicho proyecto traía consigo un "trasbordo ideológico hacia el marxismo". Para ello, Fiducia decidió iniciar una campaña nacional de "esclarecimiento ideológico" en contra de las ideas del agro-reformismo de izquierda de las cuales se inspiraba el gobierno democratacristiano.

Al inicio del documento, Fiducia dejaba en evidencia la disputa que estaban llevando a cabo en contra de todo un contexto político-social abierto a los cambios estructurales (Dooner, 1984: 73). ${ }^{9}$ Al respecto enunciaba:

8 El Mercurio, 26 de febrero de 1966, pp. 23-25.

9 En relación con este punto, Patricio Dooner señala que las federaciones estudiantiles de- 
Es que sopla sobre Chile como un viento, una tendencia de antipatía hacia la propiedad privada (...) la opinión pública había visto cómo se presentó un proyecto de reforma constitucional que deja al derecho natural de propiedad privada, sin garantías, al arbitrio del Estado.

A partir del esclarecimiento de los verdaderos motivos de la reforma agraria, Fiducia asumió la labor contrarrevolucionaria que el resto de "las derechas" (en especial sus partidos históricos) no estaban realizando. En ese contexto la revista realizaba esfuerzos dramáticos por argumentar doctrinariamente las verdaderas consecuencias de la reforma agraria (González, 2007: 94) asumiendo su rol protagónico en esta lucha:

“(...) 'FIDUCIA' cree, sin desconocer la significación o el alcance de tales argumentos, que la 'Reforma Agraria' debe ser encarada desde el prisma terminante y definitorio de los principios; ya que, de otro modo, carecerá de fuerza cualquier patriótico movimiento de opinión que se levante en contra de las tesis ideológicas del gobierno y no alcanzará así el que, desde el fondo de nuestra alma de chilenos, anhelamos quienes para nuestra patria queremos la grandeza y prosperidad (...)" (Fiducia, N²2, febrero-marzo, 1966: 2).

Coherente con ello, la revista sostenía que la modificación de la propiedad implicaba atentar contra el orden natural. A su juicio, la reforma perseguía el mito de la "igualdad completa", la cual constituía el núcleo ideológico del proyecto del gobierno. Ello explicaría que la reforma no estaba fundamentada en razones técnicas sino ideológicas por su interés en "exterminar el derecho de los individuos" por parte del "estatismo dirigista", contrario a la ley natural y la ley divina.

Es notable, por otro lado, constatar que nuevamente la estrategia de radicalizar el problema tuviera repercusiones en la derecha tradicional. La adhesión pública del diputado liberal Gustavo Monckeberg ${ }^{10}$ y la del senador Enrique Curtis, parte de la Comisión de Agricultura de la Cámara Alta, dieron cuenta de aquello (Fiducia, № 22, febrero-marzo, 1966: 11). De allí que, tanto las páginas de la revista como en sus comunicados públicos de 1966, dieran cuenta del giro anticipado en la cultura política de la derecha que canalizó sus estrategias políticas a través de la movilización callejera para disputarle terreno a la democracia cristiana y la izquierda. Lo dicho puede ser ejemplificado en el listado de firmas de miles de universitarios derechistas

mocratacristianas, por ejemplo, cumplieron una labor en la difusión a favor de los cambios con pintadas en los muros como "Viva la Reforma Agraria; Muerte al Latifundio"; Tierra para los campesinos con la Reforma Agraria del Gobierno" o "Abajo la Oligarquía".

10 El Mercurio, 10 de marzo de 1966, p. 24. Aparecido también en cartas al director de Fiducia, $N^{\circ} 22$, febrero-marzo, 1966, Santiago, p.11. 
de todo el país apoyando la campaña de Fiducia contra la reforma agraria. Entre los firmantes aparecieron Javier Polanco, Héctor Riesle, Gonzalo y Diego Izquierdo, Jaime Widow (hermano de Juan Antonio y Andrés, de Tizona), Jovino Novoa, Eliodoro Matte, entre otros. Por cierto tal listado fue publicado en El Mercurio, el 20 de agosto de ese mismo año ${ }^{11}$.

No obstante, la ofensiva integrista no quedaría ahí. En el mismo número del Manifiesto, el director de Fiducia, Patricio Larraín, se formulaba la siguiente pregunta: ¿Es lícito a los católicos discordar del proyecto de Reforma Agraria del Presidente Frei? en respuesta a una declaración del Cardenal Raúl Silva Henríquez a la revista Ercilla del 5 de enero de 1966, en la cual el magisterio apoyaba oficialmente el proyecto de reforma, pidiendo a los católicos apoyarlo. En virtud de ello, Larraín sostenía que el Cardenal no dejaba en claro en la entrevista que la reforma se ajustaba a la doctrina social de la Iglesia. Lo que llevó al autor a insistir nuevamente en la tesis del "trasbordo ideológico" hacia el marxismo del catolicismo de "tercera posición", aunque poniendo énfasis en aquellos católicos que no estaban de acuerdo con los planteamientos del Cardenal Raúl Silva Henríquez, esgrimiendo que él no daba cuenta de que el proyecto de reforma era absolutamente incompatible con la doctrina social de la Iglesia (Fiducia, N²2, febrero-marzo, 1966: 8). Precisamente estos "malos católicos" serían todos aquellos que cuestionaban el orden social tradicional que adquiriría una nueva denominación: "izquierdismo católico", que sería el punto con que Fiducia arremetería en los años posteriores al golpe.

Por otro lado, la agrupación insertó otro documento aparecido en El Mercurio, del 27 de agosto del mismo año, titulado: ¿Ceder para no perder? ¿Luchar para no perder?, en donde la revista, con un tono radical y decisivo en la lucha contra la revolución llamaba abiertamente a un enfrentamiento ${ }^{12}$. La lucha contra la "revolución comunista" se consideraba una verdadera empresa por la causa de Dios y la patria. Según Fiducia habría llegado el momento final de acabar con el enemigo:

"(...) en esta hora histórica, Fiducia levanta su voz para afirmar que cuando se trata de defender cuestiones vitales para nuestra Patria, el 'ceder para no perder' importa traicionar; y para afirmar que la voz del patriotismo frente a esa amenaza interna dice, al igual que

11 Véase El Mercurio, 20 de agosto de 1966, p. 12

12 Posteriormente durante la UP, este comunicado de Fiducia sería utilizado en la discusión parlamentaria de la comisión investigadora encargada de conocer los actos de violencia ocurridos con la aplicación de la Reforma Agraria, a raíz del asesinato del director zonal del CORA, de la ciudad de Linares, Hernán Mery, perpetrado por latifundistas. El diputado del PC, Luis Tejeda, leyó la mencionada declaración de Fiducia en respuesta al diputado Mario Arnello del PN, quien restaba de responsabilidad a la violencia de los propietarios latifundistas. Véase Chile. Congreso Nacional. Sesión Ordinaria N 19, 4 de agosto de 1971, pp.1.695-1.699. 
frente a una invasión externa, que la única actitud digna es 'luchar para no perder'".

Luego en un tono amenazante concluía:

Fiducia hará todo para movilizar a la opinión pública (...) Si ella no venciese esta batalla, estará preparando las fuerzas vivas de la nación para las recuperaciones del día de mañana (El Mercurio, 27 de agosto, 1966:19).

De lo dicho arriba se podría sostener que el documento de Fiducia apelaba a que en algún momento vendría el enfrentamiento violento con el enemigo, tal como aconteció con el golpe de Estado de 1973, culminación de tal proceso. Sin embargo, el enemigo de Fiducia tenía la particularidad de ser omnipresente y una vez derrocado el gobierno del presidente Allende, el enemigo se trasladaba a otro potencial lugar: la jerarquía de la Iglesia Católica (en especial la figura del Cardenal Silva Henríquez) y todas las organizaciones de defensa de los derechos humanos.

Digamos, entre paréntesis, que el debate sobre la reforma de la propiedad también contempló un campo de disputa en la significación de lo católico. Disputa que, por cierto, constituía una manifestación del contexto de polarización del país hacia la izquierda de los sectores progresistas católicos y su respuesta por parte de los más conservadores. En esta tarea de construir (y manipular) unos usos lingüísticos que vincularan al gobierno democratacristiano como antesala de la revolución comunista fue la tarea prioritaria de este portavoz de la extrema derecha chilena que -sin lugar a dudas- amplificó los antagonismos que fraccionaban al conjunto de la sociedad, erigiéndose como una caja de resonancia para la clase propietaria no expropiada por el gobierno.

\section{Tizona $^{13}$. En búsqueda de los garantes de la nación católica: las Fuerzas Armadas}

13 La revista tomó el nombre de una de las espadas del Cid Campeador (héroe mitológico católico hispano). Fue fundada por el Doctor en Filosofía y profesor de la Universidad Católica de Valparaíso, Juan Antonio Widow Antoncich -integrante del Movimiento Revolucionario Nacional Sindicalista (MRNS), organización hispanista fundada en 1952-, y por su hermano Andrés Widow, en 1958, en Viña del Mar, publicando algunos números ese año. Sin embargo la revista apareció justo en el último año de gobierno de Frei Montalva en 1969, con un panorama político cada vez más polarizado hasta dejar el año 1975 por razones económicas. Entre sus columnistas más importantes se destacaron el sacerdote Osvaldo Lira, mentor de Jaime Guzmán y Juan Antonio Widow; el historiador Julio Retamal Favereau y Gonzalo Ibáñez Santa María, entre otros. 
La otra revista en cuestión es Tizona que utilizó unos usos lingüísticos destinados a identificar el período previo a la Unidad Popular como un auténtico desbordamiento revolucionario y de sensación incontrolable de anarquía. A partir de ello, Tizona enfatizó en la desidia del gobierno democratacristiano con la institución militar debido a la drástica reducción de su presupuesto económico producto del excesivo gasto estatal por sus reformas sociales.

Así, Tizona iniciaba su primera edición de 1969 con un discurso que asociaba en términos absolutos "chileno" con "católico". Frente a la eventual llegada al poder de Salvador Allende, la revista pretendía enfatizar que su gobierno terminaría con los pilares esenciales de la nación. Ante ello, Tizona buscaba revitalizar el vínculo entre catolicismo-nacionalismo y Fuerzas Armadas. Para tales fines los militares cumplían una misión privilegiada para restablecer la unidad nacional en la construcción de un orden nuevo bajo principios cristianos.

En su primera editorial de julio de 1969, la revista construyó paulatinamente su postura antidemocrática en la que evaluaba la actual crisis como resultado del desorden y la violencia consustancial de todo régimen demoliberal, y del cual no existía ninguna otra alternativa que enfrentarla.

“ ¿Por qué entonces si la intención es la de manifestar razones, tomar como símbolo y nombre el de un arma? Es errado pensar que el que se sitúa en la perspectiva de la inteligencia se transforme por ello en un ente pasivo y neutral. La espada sólo se justifica por la verdad que con ella se defiende, y la verdad, por su parte, exige ser defendida" (Tizona, № 1, julio, 1969:1).

La revista realizaba un abierto llamado a empuñar la Tizona para defender la "verdad" y, en virtud de ello, establecer un espacio de enunciación tendiente a impulsar al Ejército a intervenir en la vida política, entendiendo a éste como actor indispensable para el funcionamiento y la pervivencia de la nación. Al respecto, Tizona retrotrajo el problema presupuestario del ejército en el gobierno de Frei a través de un artículo de Andrés Widow titulado ¿Están preparadas las Fuerzas Armadas?, en el cual criticaba el presupuesto económico del gobierno democratacristiano a las Fuerzas Armadas que, como consecuencia, produjo el abandono de la institución de muchos soldados por falta de un horizonte profesional y bajos salarios. Al respecto, Widow se formulaba cuestionamientos ante la situación de los militares

"(...) Si es necesaria la inversión económica para mantener las Fuerzas Armadas, ¿es conveniente que sea lo más baja posible, debido a que existen otras necesidades nacionales, arriesgando con ello el que en un momento determinado puedan aquellas estar impedidas para cumplir sus funciones por falta de medios?....)" (Tizona, N 1, julio, 1969:1-2). 
Lo anterior llevó al mismo Widow a presuponer que el régimen democrático era contrario al código de valores de los militares, por lo que había que exaltar las cualidades, virtudes y capacidad de sacrificio de las FF.AA., en tanto que baluartes de la pervivencia de la nación. En tal sentido, Widow señalaba en Fuerzas Armadas, democracia y patriotismo:

“(...) Las Fuerzas Armadas son la columna vertebral de la Nación, son las que mantienen vivos los sentimientos de amor patrio, orden y disciplina, honor y abnegación, eficiencia y sentido del deber (...) Chile es lo que es gracias a sus Fuerzas Armadas y su futuro como Nación depende de que ellas cumplan su función" (Tizona, $\mathrm{N}^{\circ} 2$, agosto, 1969:3).

Desde la perspectiva del autor, sí la democracia atentaba contra el ejército al mismo tiempo lo hacía contra la nación. En ese sentido, el gobierno de Frei y el sistema democrático socavaban los cimientos de la historia de la patria. En las condiciones del sistema demoliberal sólo estarían primando los intereses partidistas, y no precisamente del bien común.

A lo anterior se puede agregar que todos los artículos dedicados exclusivamente al problema de las FF.AA generarían consecuencias en los cuarteles del ejército. Los análisis hechos por Tizona fueron discutidos por los oficiales, al punto que los altos mandos decidieron requisar la revista para mantener la disciplina (Corvalán Márquez, 2002: 134).

En este marco, el problema de las FF.AA desarrolladas en sus artículos por Tizona tuvieron puntos de convergencia con otros grupos de extrema derecha como el grupo Tacna, especialmente con el General Roberto Viaux Marambio quien exigía la renuncia del Ministro de Defensa y del Comandante en Jefe del Ejército, producto de los problemas que afligían a las FF.AA. Petición que, por cierto, recibió el respaldo de la mayoría de la oficialidad de las tres ramas del ejército. ${ }^{14}$ Agréguese además el apoyo brindado por otras colectividades como el Partido Nacional, Ofensiva Libertadora, entre otros. De este modo, de lo arriba expuesto, se podría sostener que en la creciente politización de las FF.AA, Tizona fue la única formación que estaba detrás de ello.

Paralelamente a lo anterior, Tizona fue paulatinamente perfilando su proyecto de sociedad y aprovechó la sublevación militar del Tacnazo para enfatizar sobre el agotamiento del sistema liberal y substituirle por un sistema

14 Después del Tacnazo el General Roberto Viaux, el Mayor Rolando Orellana, el Capitán Víctor Manuel Mora y el teniente Raúl Munizaga fueron procesados por la justicia militar por sedición o motín. Por otra parte, cabe señalar que detrás del Tacnazo hubo apoyo de movimientos nacionalistas de izquierda, tercermundistas, los cuales admiraban la experiencia del General Velasco Alvarado en el Perú, quien nacionalizó las riquezas básicas y realizó una reforma agraria. Véase al respecto Valdivia (1998). 
corporativo. En tal línea, Juan Antonio Widow, en un artículo titulado Nuestra crisis política y las Fuerzas Armadas, expuso abiertamente la necesidad de acabar con el proceso de descomposición total del país, presentando a las FF.AA como las únicas efectivas en reponer el orden e instaurar una dictadura, retrotrayendo el imaginario idílico del orden "portaliano" que se impuso durante todo el siglo XIX en Chile.

"(...) Lo único que puede salvar a nuestro país de la descomposición total a la que se dirige sin freno es el surgimiento de una nueva clase dirigente con cualidades y capacidades análogas a la portaleana. Un hombre solo no puede realizar esta obra, por extraordinario que sea su valor, como no habría podido haber hecho nada Portales al haber confiado exclusivamente en su generalidad y no hubiese dado al Estado una forma capaz de trascender el plano de las individualidades (...)" (Tizona, № 5, octubre, 1969: 5).

Se puede desprender de esta cita que la violencia que conllevaría tal instauración autoritaria, sin dudas, estaba en función de un fin justo. La consecución de salvar a la nación de su descomposición moral justificaría tal violencia y la construcción corporativa de la sociedad. De allí que el mismo Widow, en otra editorial titulada Entre el Capitalismo y Socialismo, de marzo de 1970, estableciera diferencias entre el proyecto corporativo frente al capitalismo y socialismo que -según el autor- estarían construidas bajo el egoísmo de intereses particulares.

"En el socialismo y el capitalismo el hombre, la persona, desaparece, absorbido por entes monstruosos y anónimos. No hay oposición absoluta entre ambos: los opone sólo la lucha por el poder, esencia y motor de todo sistema basado en la voluntad o el interés y no en la inteligencia (...)" (Tizona, № 9, marzo, 1970:1).

A partir de lo mencionado anteriormente se podría sostener que Tizona apelaba a las FF.AA como único actor que terminaría el estado de caos y desorden en que se encontraba el país. Tales enunciaciones de la revista permitieron no sólo argumentar en contra del sistema demoliberal y los partidos políticos sino también instrumentalizar el miedo ante la eventual llegada al poder del marxismo. Ello terminó por generar repercusiones políticas dentro de las propias FF.AA., llevando incluso al requisamiento de la revista para evitar cualquier acto de sublevación o indisciplina. Por otro lado, es interesante destacar la recuperación de la historia, en particular del orden portaliano del siglo XIX, como un modelo análogo en donde se encontraría el orden ideal para Chile, agobiado por un sistema demoliberal que por sí mismo avanzaba hacia su propia autodestrucción (Pérez, 2010: 57).

Mientras tanto el estado generalizado de miedo y ansiedad a meses de la próxima elección presidencial -en la que triunfó el candidato de la Unidad 
Popular, Salvador Allende (1970-1973)- generó toda una expectación en Tizona sobre cuál sería el próximo escenario que debían enfrentar ante el eventual triunfo de la izquierda. En efecto, para Juan Antonio Widow, en su editorial del mes de mayo y junio de 1970, las elecciones no cambiarían en nada la situación política del país, a menos que se estableciera un régimen de autoridad. Desde esta perspectiva, la lucha que emprendía el Partido Nacional -a su juicio- en el marco político democrático no tendría validez para derrotar al marxismo, pues, serían parte de ese "juego democrático" que tanto criticaba la revista desde sus inicios.

El clima del período pre-eleccionario en que actualmente vivimos los chilenos es, como en anteriores ocasiones, causa de enajenación colectiva.

"(...) En estos momentos se hace legítimo el odio, el insulto, el ataque con cualquier arma; en suma, la destrucción por cualquier medio del adversario. A esto se llama, eufemísticamente, contienda "política" (...)" (Tizona, No 10, octubre, 1970:1-2).

El despliegue argumentativo de crear un clima de anarquía que permitiera demostrar la incapacidad del sistema democrático para imponer la ley y el orden llevaría como corolario a la solución para ello: la estrategia del complot contra el gobierno y el golpe de Estado. De modo que se insistía nuevamente en convencer a las Fuerzas Armadas de dar por terminado algo que podría socavar el país.

\section{La "satanización del otro" y el discurso de Cruzada: Las consecuencias del asesinato del general Schneider en Tizona, 1971}

El lapso que se extendió entre el 4 de septiembre y la ratificación de Salvador Allende por parte del Congreso Pleno fue de gran tensión política, la cual ofreció terreno fértil a Tizona para la satanización del otro y para perfilar y moldear al máximo el discurso de la cruzada. En ese sentido la izquierda buscaba los votos de la democracia cristiana para la ratificación de Allende en el Congreso, mientras que las derechas se embarcaban en toda clase de artimañas para evitar la confirmación de la Unidad Popular. El resultado de ello fue una solución golpista que daría lugar al rapto y, por un disparate, a dar muerte al General Schneider Chereau, -conocido oficial constitucionalista-, a finales de octubre de 1970. Todo ello tendría como fin culpabilizar a la extrema izquierda de su deceso y así impedir la elección de Salvador Allende.

Con respecto al atentado cabe señalar que participaron la $\mathrm{CIA}$, almirantes de la Armada, Generales del Ejército, Carabineros, de la FACH y miembros de 
grupos nacionalistas, entre los que se encontraba Andrés Widow, encargado de secuestrar a Schneider, y quien fuera condenado en 1971 por la justicia militar como autor de secuestro con grave daño a la persona del general, a la pena de tres años de presidio menor ${ }^{15}$. Demás está decir que entre los otros involucrados se encontraron dos miembros de Fiducia, Juan Luis Bulnes y Diego Izquierdo Menéndez y Allan Leslie Cooper; Jorge Solminihac; Guillermo Carey; Jorge Arce y Enrique Arancibia Clavel. Este último vinculado ideológicamente a Tizona y, paralelamente, formó parte de la Juventud Nacional, Ofensiva Nacionalista y de la Brigada Obrera Campesina (BOC) donde proporcionaba las dinamitas y coordinaba a los participantes realizando diversos actos de terrorismo, -de supuesto origen izquierdista-, entre el 18 de septiembre al 11 de octubre de 1970, que incitaban a la evaluación crítica del sistema democrático liberal (Valdivia, 2008: 275).

El asesinato del general Schneider generó repercusiones a nivel mundial. El periódico español $A B C$ incluyó en sus páginas una nota titulada Personalidades políticas de la derecha, implicadas en el asesinato del General Schneider, aparecida el 31 de octubre de $1970^{16}$.

En Chile, por su parte, la imagen de Andrés Widow apareció en la revista Punto Final-del Movimiento de Izquierda Revolucionaria (MIR)-, acusándolo de ser uno de los asesinos del general Schneider. Además se le reconoció como ex oficial de la Marina y subdirector del "periódico derechista" Tizona17.

Como es obvio, el columnista de Tizona dejó de escribir en la revista y el atentado terrorista terminó por empujar a la democracia cristiana a confirmar a Allende como presidente el 24 de octubre, con una votación de 135 votos por sobre los 35 de Jorge Alessandri. Lo cual, en fin, determinó la estrategia de convencer doctrinariamente a las Fuerzas Armadas a que intervinieran en la política de manera permanente.

A partir de lo dicho arriba, Juan Antonio Widow afirmaba que no hubo detrás del grupo, en ningún momento, la intención de asesinar al general Schneider, y que sólo tenía por objetivo apresarle para una acción posterior. Este autor exculpa a su hermano Andrés tratando de responsabilizar del atentado al MIR, quienes -añade- se habrían infiltrado en el ejército para secuestrar al mencionado general.

Por otro lado, Allende -ya designado Presidente de la República- había iniciado la "vía chilena al socialismo", y Juan Antonio Widow culpabilizaba

15 Revista de Derecho, Jurisprudencia y Ciencias Sociales y Gaceta Jurídica. Santiago de Chile: Editorial Jurídica, 1972, p. 308.

16 Diario $A B C, 31$ de agosto de 1970.

17 Para más información, véase Punto Final, 10 de noviembre de 1970, Santiago, p. 5. 
al gobierno de Frei Montalva por las facilidades que le dio a la Unidad Popular para llegar al poder; al mismo tiempo que criticaba al anticomunismo del resto de la derecha que se preocupaba más de sus posesiones de tierras que de enfrentar al enemigo. Las palabras de Widow, por tanto, permitieron darle un elemento de sacrificio, de esfuerzo, de cruzada, a los defensores de los valores de la nación, quienes frenarían la implantación de un régimen político subordinado al imperialismo soviético. Los enemigos -en tanto que representantes del mal- serían combatidos no sólo con las armas sino además con la fe. Al respecto, Widow señalaba:

"Tal actitud no se gana sin una vida religiosa; es decir, una vida de fe y de oración. Sin un conocimiento, proporcionado de la formación intelectual de cada persona -producto, en consecuencia, del estudio-, de las verdades fundamentales de la fe católica" (Tizona, № 17-18, noviembre-diciembre, 1970: p. 2).

La cita anterior resulta interesante puesto que la apelación a la religión en la resistencia al marxismo constituía no sólo la demonización del otro (de la Unidad Popular y toda la izquierda, en este caso), sino de preparación para la confrontación final entre el Bien y el Mal, una cruzada, contra los "enemigos de Dios". En ese sentido, Dios estaría del lado de aquellos que pretenden una nueva patria bajo un régimen de autoridad.

\section{Conclusiones}

En conclusión, a partir de todo lo dicho se podría afirmar que estas revistas generaron unos usos lingüísticos que descalificaron absolutamente al contrario en donde el terror y miedo pasaron a convertirse en su principal recurso para legitimar el modelo autoritario de ordenamiento político y jerárquico de organización social. Todo ello, por cierto, constituía el justificativo del golpe de Estado, considerado justo ante unos enemigos portadores de todo tipo de perversidades y flaquezas que deterioraban la salud patria. Lo cual explica los usos lingüísticos de Fiducia y Tizona, a saber: demonizar a ciertos sujetos; provocar miedo en otros; y convencer a los militares de que debían dar un golpe salvífico orientado a la destrucción de aquella entidad que sus discursos identificaran como el Mal absoluto.

Ahora bien, en el caso de los usos lingüísticos de Fiducia resultaron efectivos para la rearticulación política de la derecha con carácter proyectual durante la década del sesenta, ya que -según su visión-se estaban viviendo momentos decisivos en la lucha histórica contra la revolución que había comenzado siglos antes. Esta revolución, por cierto, presentó un carácter omnipresente, la cual establecía un marco de significación de "cruzada" permanente a sus miembros para defender los "valores inmutables" que estaban en peligro, 
incluso hasta después del golpe militar, cuando el enemigo pasó a ser la Iglesia Católica, defensora de los derechos humanos.

Por otro lado, Tizona, desde un principio, mostró un discurso de enfrentamiento y descalificación total, sin concesiones, encarnado en la democracia liberal y el marxismo. Estos últimos constituían la negación de la "nación católica" -en tanto que degradantes del orden social tradicional-, los cuales se transformaron en un adversario susceptible de ser eliminado -incluso físicamente-. En ese sentido el "marxismo" -ya en el poder- degradaba todos los aspectos de la sociedad, por lo cual había que iniciar la "cruzada" en contra de la izquierda y del presidente Allende, siempre intentando convencer a los militares de que debían instaurar una dictadura salvífica de tipo refundadora. La imagen del enemigo omnipresente (quien nunca será derrotado puesto que se divide en distintos sujetos) mientras más omnipresente sea, más necesaria sería la represión y violencia contra él. Sin lugar a dudas los miles de detenidos desaparecidos durante la dictadura militar fueron un fiel testimonio de aquello.

\section{Referencias bibliográficas}

\section{Fuentes primarias}

Congreso Nacional. Sesión ordinaria N 19, 4 de agosto de 1971

Diario ABC, 31 de agosto de 1970. Disponible en internet: http://hemeroteca. abcdesevilla.es/nav/Navigate.exe/hemeroteca/sevilla/abc.sevilla/1970/10/31/037. html

El Diario llustrado

El Mercurio

Fiducia

Punto Final

Tizona

\section{Fuentes secundarias}

CORVALÁN MÁRQUEZ, L. (2002). Del anticapitalismo al neoliberalismo en Chile. Santiago de Chile: Editorial Sudamericana.

DOONER, P. (1984). Cambios sociales y conflicto político: el conflicto político nacional durante el gobierno de Eduardo Frei (1964-1970). Santiago de Chile: ICHEH.

GONZÁLEZ, E. (2007). Las derechas chilenas. Mediados del siglo XX al golpe de 
Estado de 1973. Valparaíso: Tesis de grado para optar al grado de licenciado en Historia, Universidad de Valparaíso.

MERINO, J.T. (1998). Bitácora de un almirante: memorias. Santiago de Chile: Editorial Andrés Bello, 1998.

PÉREZ, A. (2010). Dios, Nación y Destino. El imaginario político del Movimiento Revolucionario Nacional Sindicalista. Valparaíso: Tesis para optar a los Grados de Licenciado en Historia, Universidad de Valparaíso.

VALDIVIA, V. (1998). Todos juntos seremos la Historia: Unidad Popular y Fuerzas Armadas. En: PINTO, J. (coordinador). Cuando hicimos historia: la experiencia de la Unidad Popular. Santiago de Chile: Editorial LOM, 182 pp.

VALDIVIA, V. (2008). Nacionalistas y gremialistas: el "parto" de la nueva derecha politica chilena, 1964-1973. Santiago de Chile: LOM Editores. 